\title{
presa celular
}

$531-36$

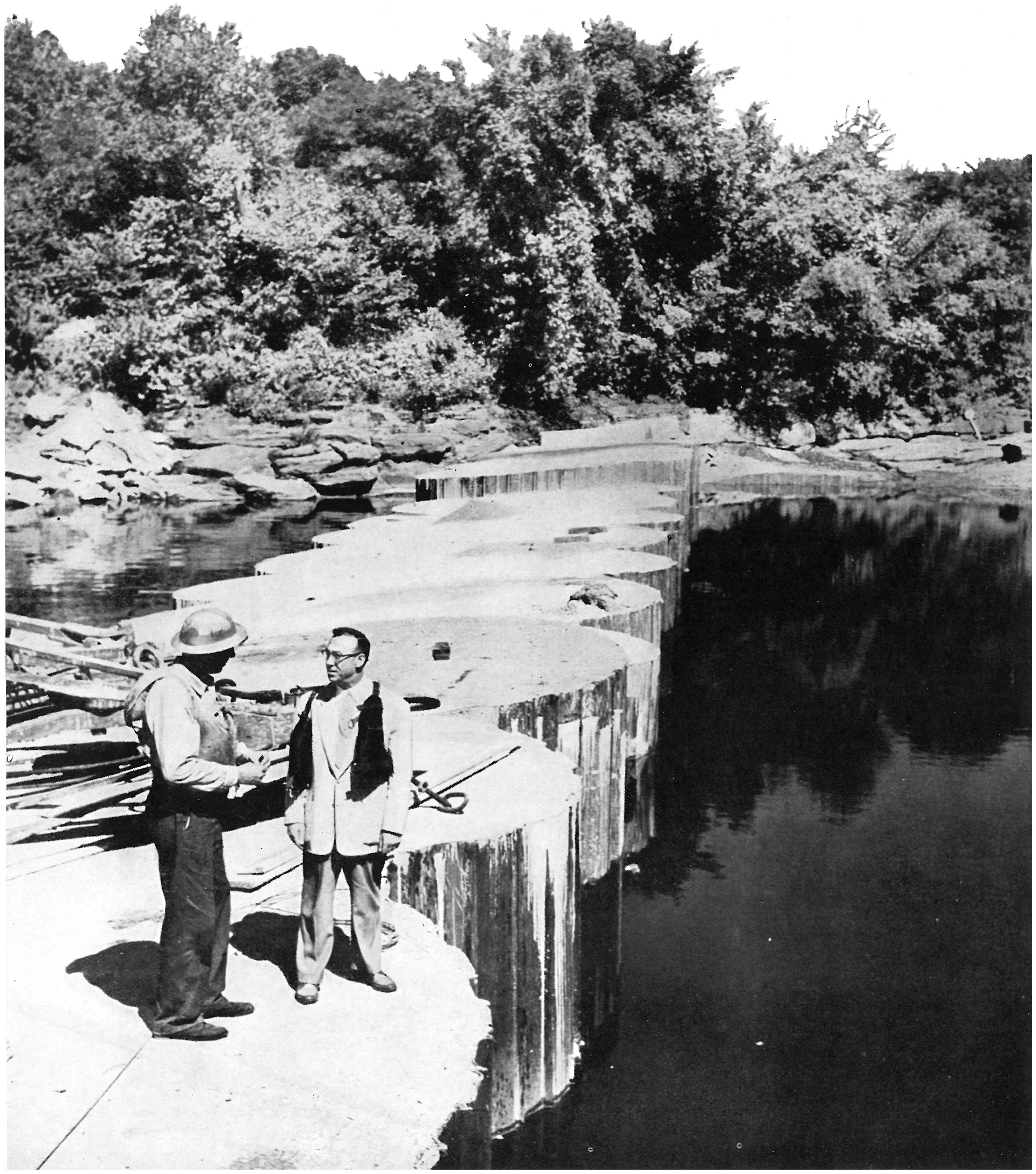

(c) Consejo Superior de Investigaciones Científicas Licencia Creative Commons 3.0 España (CC-by) 


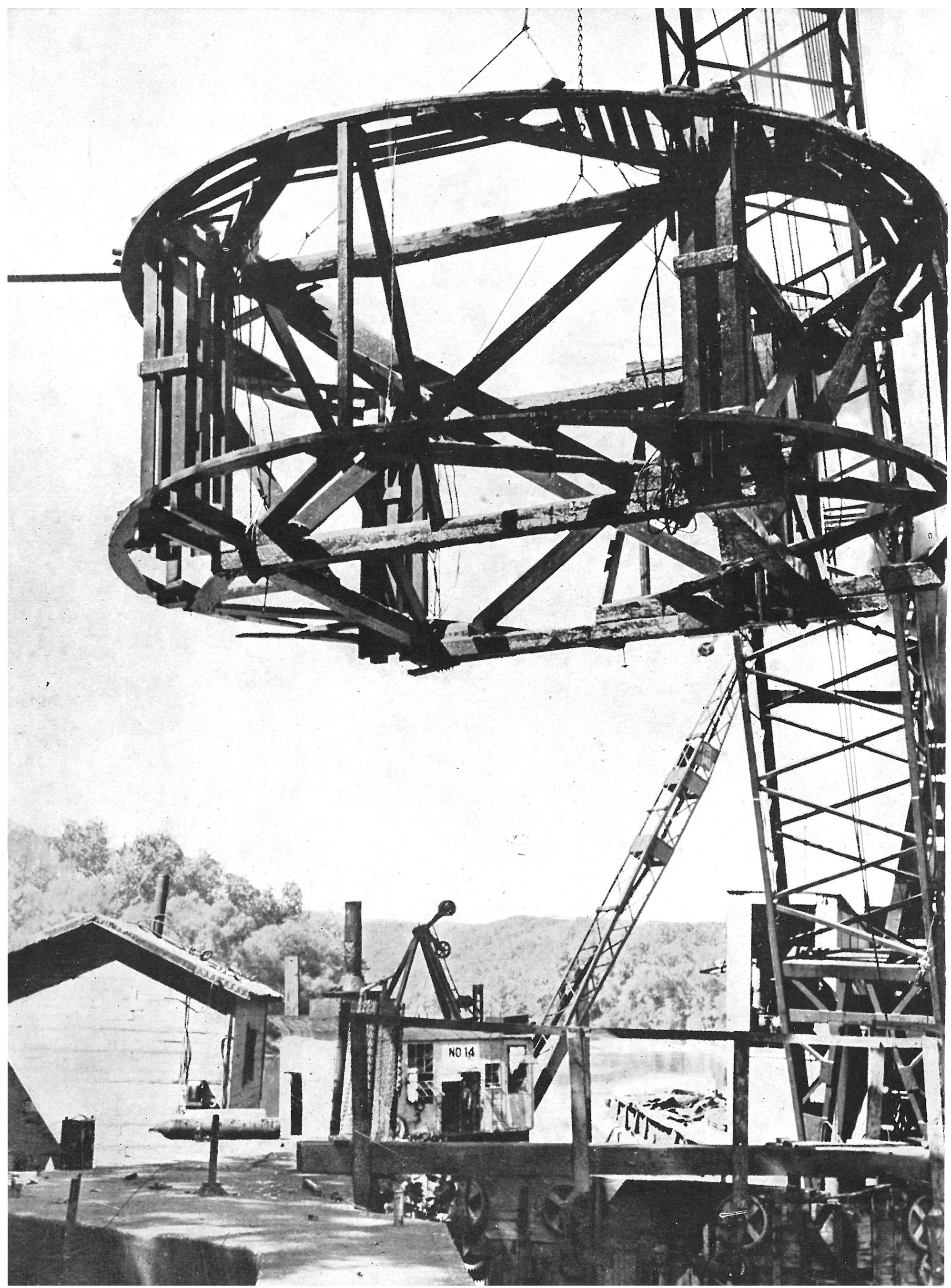




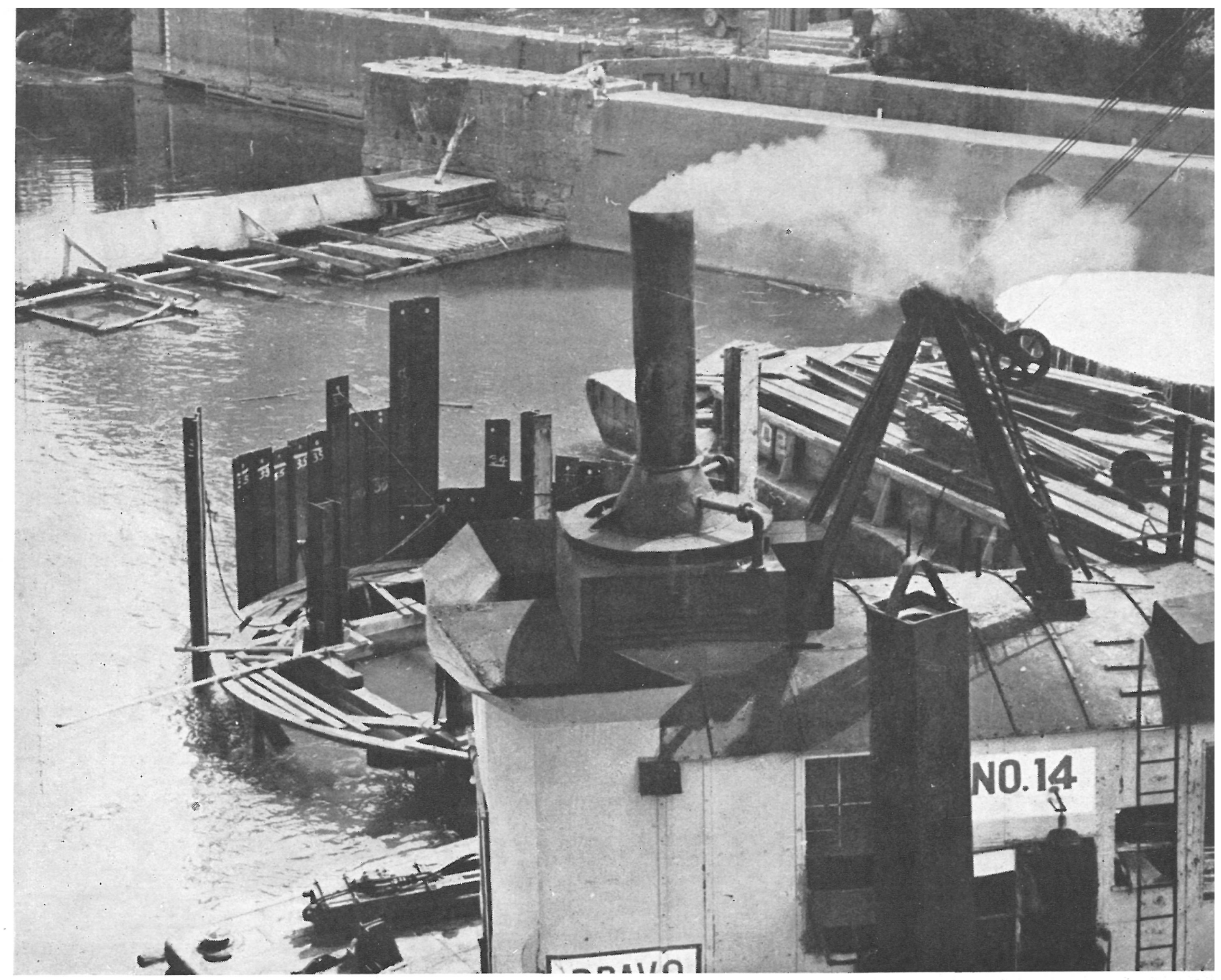

La factoría de la American Viscose Corporation de Parkersburg, situada en Parkersburg, West Virginia (EE. UU.), venía disfrutando del agua embalsada por una presa rudimentaria cuya estructura estaba constituída por un entramado de madera.

Esta presa original se extendía sobre el pequeño río Canawha, que, aunque navegable y afluente del Ohio, no presenta dificultades en su régimen normal ni en la navegación, pues ésta ha cesado hace mucho tiempo en su explotación y conservación. Para salvar la presa se había construído una esclusa. El azud se apoyaba en una de sus dos extremidades, sobre el muro exterior de la referida esclusa.

Como la presa presentaba serios desperfectos y debía repararse, la Empresa que se abastecía de las aguas que proporcionaba el embalse estudió detenidamente las soluciones más interesantes para asegurar la continuidad de abastecimiento de agua. La solución final resultó ser la de una estructura celular, obra que se confió a Dravo Corporation, de Pittsburgh, Empresa constructora especializada en presas y ataguías de este tipo, es decir, formando células circulares con un tablestacado metálico que, para solidarizarlo, se unen entre sí por medio de dos paredes, también de tablestacas metálicas, constituyendo otro sistema adicional de células, pero, en este caso, de sección rectangular. Finalmente, estas células cilíndricas y paralelepipédicas se rellenan con un hormigón pobre, que para terminar se recrece con otro normal, constituyendo la coronación y vertedero de la presa en este caso particular. 


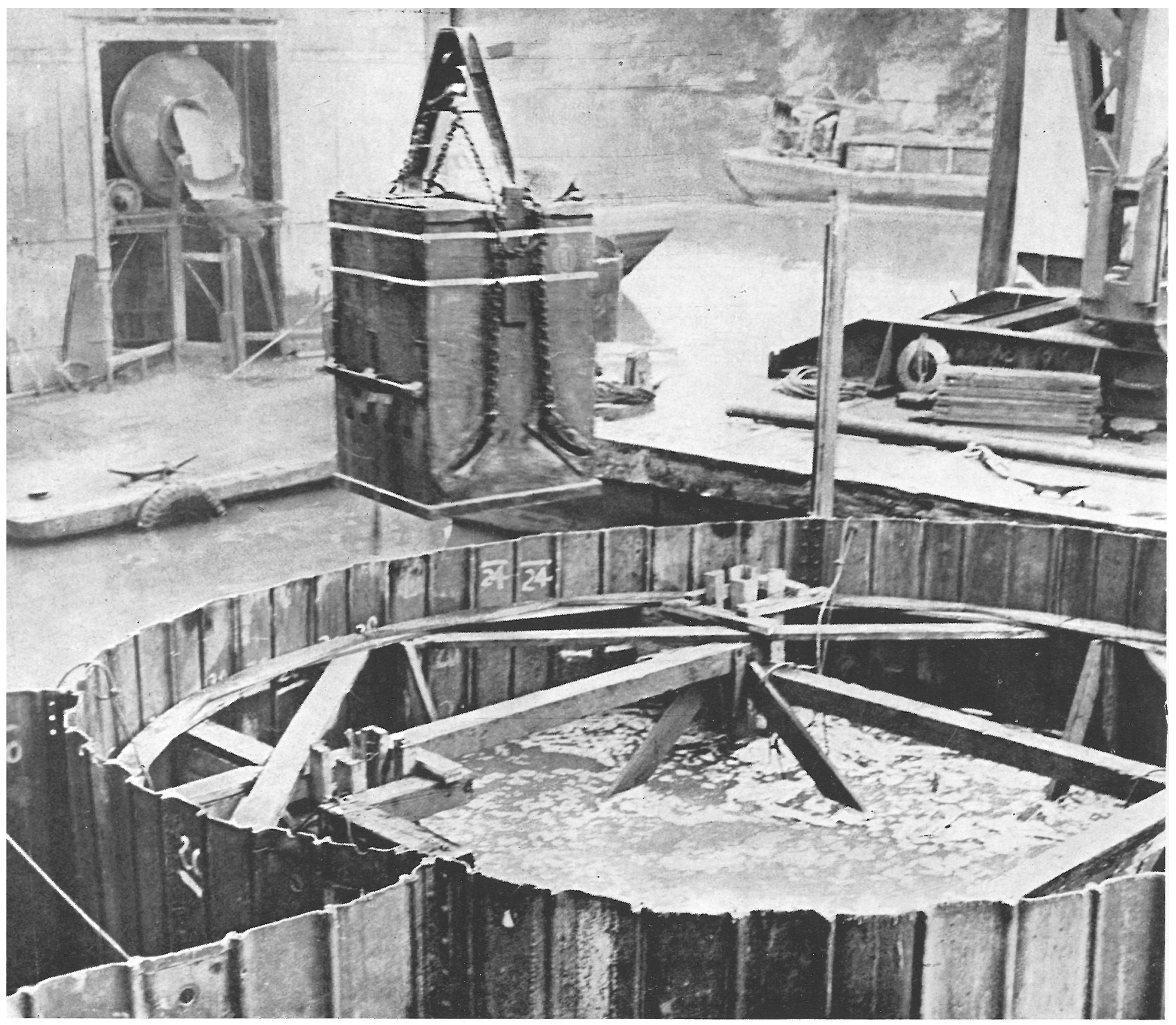

La nueva presa, que, como dijimos anteriormente, estriba contra uno de los muros de la esclusa, conservada para la derivación de aguas en caso de posible emergencia, se ha ubicado unos metros aguas abajo de la antigua estructura de madera; su longitud es de unos $91 \mathrm{~m}$, tiene 7,60 $\mathrm{m}$ de altura, y su vertedero, de $36,50 \mathrm{~m}$ de longitud, habilitado en la parte central de la presa, tiene su solera a una cota $2 \mathrm{~m}$ por encima del nivel mínimo de embalse y de $0,75 \mathrm{~m}$ por debajo del nivel lateral de coronación, recrecido para determinar diferencialmente la caja del referido vertedero.

La presa está constituída por siete células cilínalesquiera de estas siete células se ha formado otra, formado con tablestacas metálicas. Entre dos de cudricas de 8,85 m de diámetro, cuyas paredes se han 


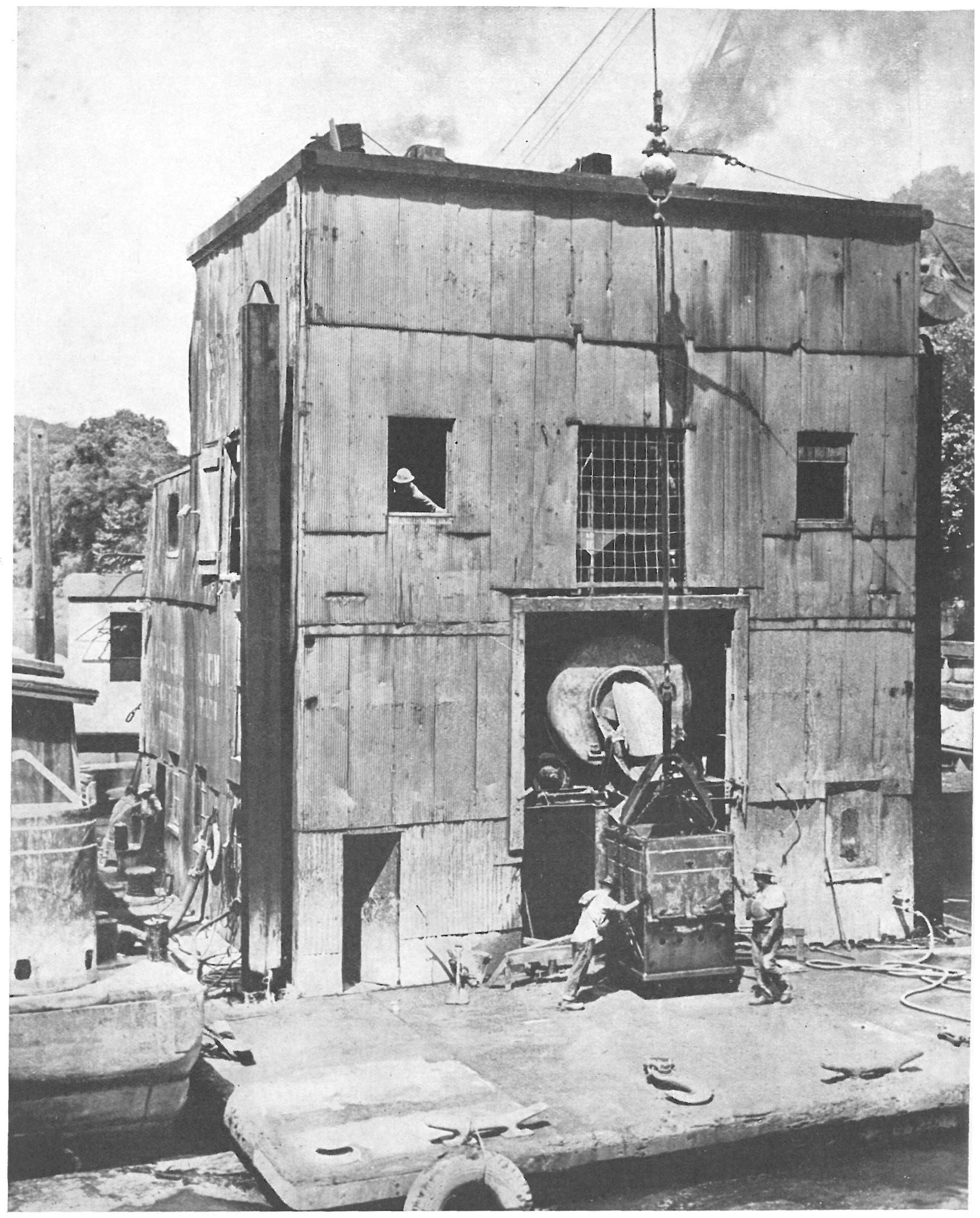

de forma paralelepipédica, que rompe la regularidad y que, en número total de seis, constituyen el muro de cierre junto con las otras de forma circular. El interior de todas estas células se ha rellenado con hormigón pobre. 


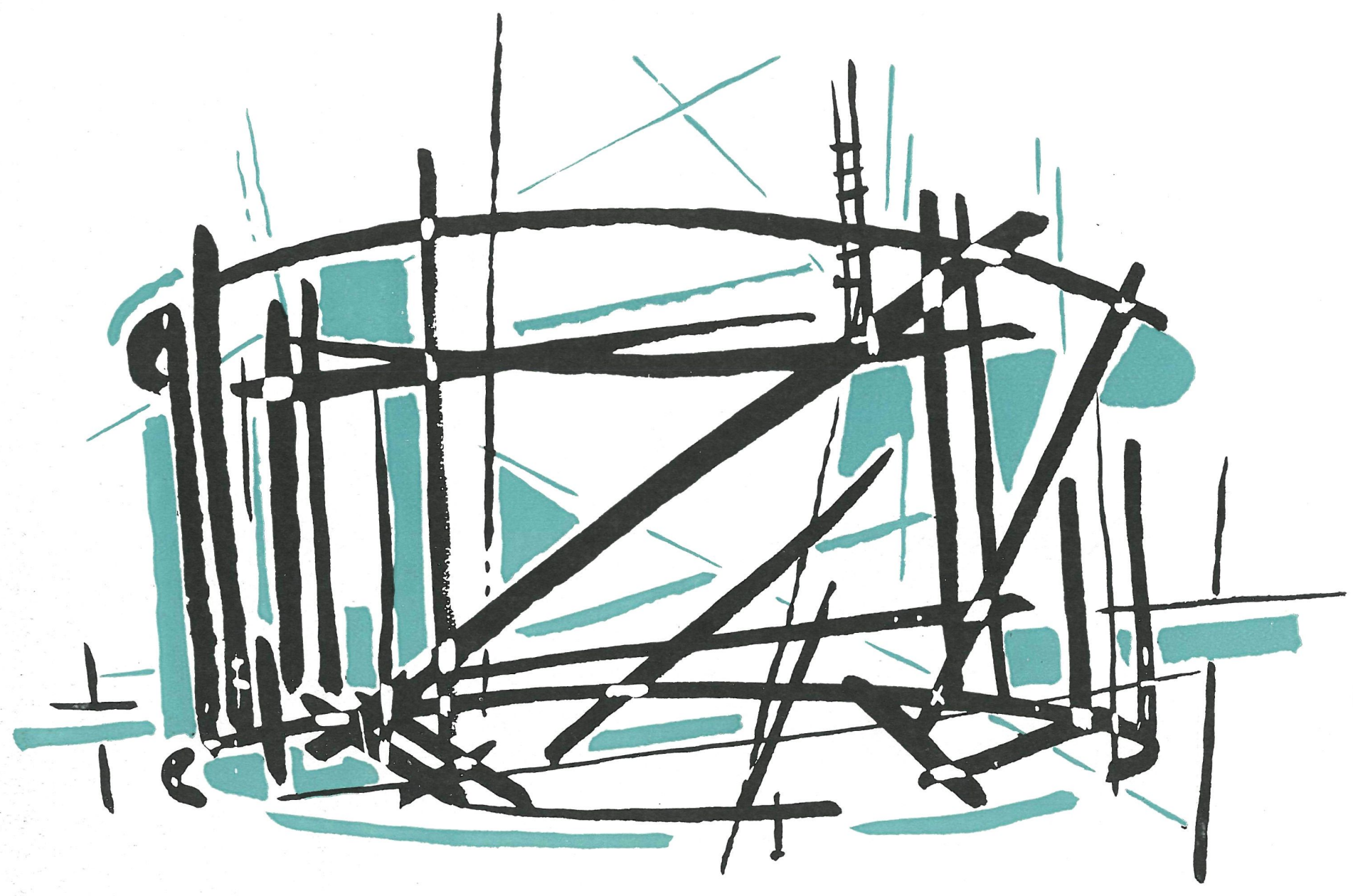

Para la hinca de las tablestacas metálicas que constituyen las paredes de cada una de las células se ha utilizado una machina montada sobre un pontón. Para la manipulación de las tablestacas y hormigón de relleno se empleó una grúa montada sobre barcaza.

Antes de proceder a la hinca de tablestacas se preparó una plantilla de madera que se descendía y se fijaba convenientemente, empezando después la hinca alrededor de la plantilla que servía de guía. La hinca se llevaba hasta la profundidad requerida, procediendo después a rellenar el anterior con hormigón pobre. Para ello se utilizó una central de preparación de hormigón que, como la machina y grúa, también era flotante. Antes de hormigonar se limpiaba el fondo de cada célula, excavando hasta llegar a la roca firme.

El hormigonado se realizó utilizando un cazo especial que se empleó para depositar el hormigón bajo el agua. Con objeto de mantener el arriostramiento debido, la plantilla de cada célula no se retiraba hasta que el hormigón llegaba a una altura tal que no era posible ninguna deformación apreciable del tablestacado. Enrasada la parte superior de las distintas células se continuaba el hormigonado, pero utilizando un cazo ordinario.

Todos los elementos flotantes, así como los materiales empleados en la construcción, fueron transportados a la obra por el río, partiendo del río Ohio.

Para la construcción de esta obra se emplearon 280 toneladas de tablestacas de acero y unos $460 \mathrm{~m}^{3}$ de hormigón.

J. J. U.

INFORMES DE LA CONSSTRUCOION 